\title{
The Maillard Reaction of DNA with D-Fructose 6-Phosphate
}

\author{
Junji MoRITA and Naoki Kashimura* \\ Department of Food Science, Doshisha Women's College of Liberal Arts, \\ Kamigyo-ku, Kyoto 602, Japan \\ * Department of Bioscience, Mie University, Tsu, Mie 514, Japan \\ Received November 19, 1990
}

\begin{abstract}
The Maillard reaction of DNA with ketoses was investigated. Several days of incubation of D-fructose 6-phosphate with deoxyribonucleotides or with polymer DNA in an aqueous buffer resulted in the formation of chromophores and fluorophores. Aminoguanidine and sodium cyanoborohydride inhibited the formation of fluorophores. Transition metal ions such as $\mathrm{Cu}^{2+}, \mathrm{Fe}^{3+}, \mathrm{Fe}^{2+}$, or $\mathrm{Mn}^{2+}$ promoted the formation of chromophores and fluorophores. Metal-chelating agents such as DETAPAC, citrate, and Desferal inhibited the formation of fluorophores. Superoxide dismutase and catalase also inhibited the formation of fluorophores. The transition metal ion-catalyzed autoxidation of $D$-fructose 6-phosphate or of the Heyns rearrangement products were to be partially involved in the glycation of DNA and subsequent formation of chromophores and of fluorophores.
\end{abstract}

The Maillard reaction is a complex series of reactions that occur between reducing monosaccharides and amines. The first step is the formation of a Schiff base between a monosaccharide aldehyde or ketone group and a free amino group, followed by the Amadori rearrangement to yield a fairly stable ketoamine compound called the Amadori product. The early stages of the Maillard reaction, resulting in the formation of the Amadori or Heyns rearrangement products, ${ }^{1)}$ are called nonenzymatic glycosylation or more accurately glycation. ${ }^{2)}$ In advanced stages of the Maillard reaction, fluorescent and yellow- or browncolored compounds are formed. Recently, it has become evident that the glycation of proteins occurs in vivo with hemoglobin, lens crystallines, collagen, superoxide dismutase, and a number of other proteins. ${ }^{3)}$ The Maillard reaction is postulated to contribute to some of the pathophysiology associated with both aging and diabetes. ${ }^{4)}$

It should be predictable that a similar reaction occurs between monosaccharides and DNA, which is another important biomolecule having amino groups. It has been reported that D-glucose and D-glucose 6-phosphate nonenzymatically modify DNA in vitro ${ }^{5)}$ and in vivo, ${ }^{6)}$ but the more detailed properties of DNA glycation reaction are unclear.

Since D-glucose is the most abundant monosaccharide in tissues in general and the concentration of D-glucose is elevated in diabetes, the studies on glycation so far have been focused on D-glucose. However, recent studies suggest that D-fructose ${ }^{7-9)}$ and pentoses are much more potent Maillard reactants than $\mathrm{D}$-glucose in vivo and might thus be significant in diabetic and age-related processes. $^{4,10)}$

On the other hand, reducing monosaccharides can enolize and autoxidize with the concomitant production of oxygen-derived free radicals, ${ }^{11,12)}$ inducing DNA strand breakage and virus inactivation during several hours of incubation. ${ }^{11,13)}$

In this report, we describe the Maillard reaction of DNA with a ketose, D-fructose 6-phosphate, and the involvement of the transition metal-catalyzed autoxidation in the reaction.

\section{Materials and Methods}

Chemicals and enzymes. D-Fructose 6-phosphate, Dglucose 6-phosphate, D-glucose 1-phosphate, and D- 
galactose 6-phosphate were sodium salts purchased from the Sigma Chemical Co. 2'-Deoxyguanosine 5'-monophosphate disodium salts (dGMP), 2'-deoxyadenosine 5'monophosphate disodium salts (dAMP), $2^{\prime}$-deoxycytidine 5'-monophosphate sodium salt (dCMP), thymidine 5'monophosphate sodium salt (TMP), superoxide dismutase (EC 1.15.1.1; from bovine blood, type I, 3050 units/mg protein) (SOD), and catalase (EC 1.11.1.16; from bovine liver, 2000 units/mg protein) were purchased from the Sigma Chemical Co. Desferal (deferoxamine mesylate) was obtained from Ciba-Geigy Ltd. Denatured single-stranded DNA was prepared by boiling calf thymus DNA (from Sigma Chemical Co., type I) for $5 \mathrm{~min}$ and then quickly cooling in an ice bath. Aminoguanidine- $\mathrm{HCl}$ was a gift from Dr. K. Nakamura, Kitasato University Medical School. Other chemicals were purchased from Nacalai Tesque Co.

Reaction of reducing monosaccharides with deoxyribonucleotides. The standard reaction mixture $(1.0 \mathrm{ml})$ contained $10 \mathrm{~mm}$ deoxyribonucleotides and $150 \mathrm{~mm}$ reducing monosaccharides in $50 \mathrm{~mm} N$-(2-hydroxyethyl)piperazine- $N^{\prime}$-2-ethanesulfonic acid (Hepes) buffer $(\mathrm{pH}$ 8.0) containing $0.5 \mathrm{~mm}$ EDTA. All solutions were sterilized by filtration through a Millipore Millex-GV filter. The reaction solution was sealed with Parafilm and incubated for 4 days at $37^{\circ} \mathrm{C}$ in the dark. Fluorescence emission was measured with a Hitachi 850 fluorescence spectrophotometer after 6-fold dilution of the reaction mixture. Absorbance spectra of the reaction mixture were measured by a Shimadzu UV-265 FW spectrophotometer after 2 -fold dilution of the reaction mixture. Fluorescence spectra were calculated by subtraction of that of the control run (monosaccharides alone) as the background fluorescence, since monosaccharides degraded with the concomitant increasing of fluorescence during prolonged incubation.

\section{Results}

\section{The Maillard reaction of $\mathrm{D}$-fructose 6-phosphate} with DNA

Various concentrations of D-fructose 6phosphate were incubated with or without added deoxyribonucleotides (10 mM dGMP) and the reaction solution was analyzed for absorbance and fluorescence. As expected from reports on the nonenzymatic glycation of proteins, ${ }^{14)}$ a gradual increase of absorbance in the $300-450 \mathrm{~nm}$ region was observed (Fig. 1). The amount of the increase of absorbance was dependent on the concentration of D-fructose 6-phosphate and was higher with added dGMP, although absorbance increased also with the reaction of D-fructose 6phosphate alone. The fluorescence excitation spectrum of the reaction solution of $\mathrm{D}$-fructose 6-phosphate with dGMP, measured at the emission of $420 \mathrm{~nm}$, showed a major excitation

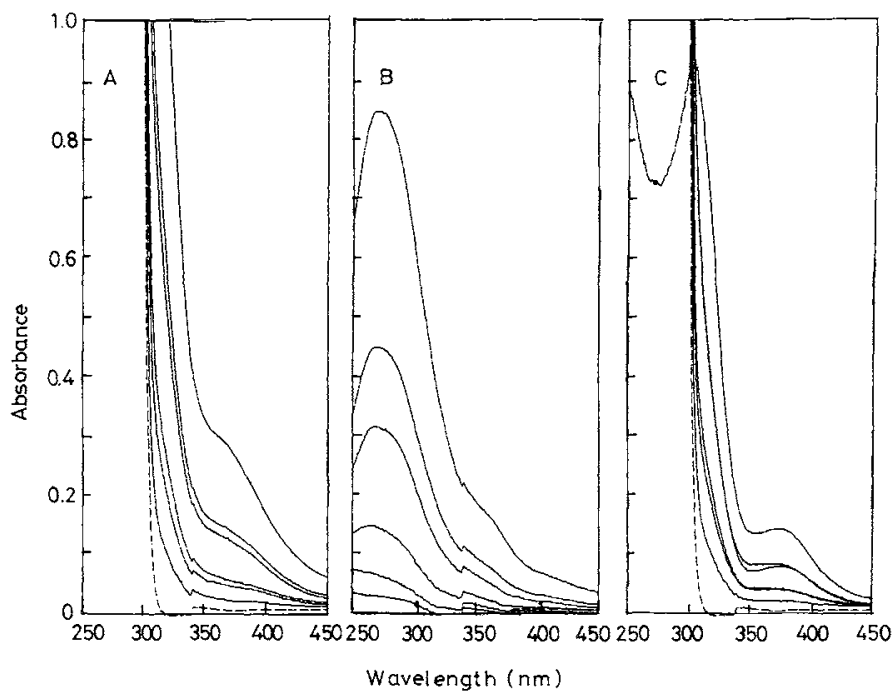

Fig. 1. Absorbance Spectra of Reaction Solutions of D-Fructose 6-Phosphate with dGMP.

D-Fructose 6-phosphate was incubated with (A) or without (B) $10 \mathrm{~mm} \mathrm{dGMP}$ at $37^{\circ} \mathrm{C}$ for 4 days in $50 \mathrm{~mm}$ Hepes buffer ( $\mathrm{pH} 8.0$ ) containing $0.5 \mathrm{~mm}$ EDTA. The reaction solutions were diluted two-fold and absorbance spectra were measured. The concentration of D-fructose 6-phosphate was, from top to bottom, 150, 100, 75, 50, 25, and $10 \mathrm{~mm}$.-..., dGMP alone; C, Difference spectra (A-B). 
maximum at $315-320 \mathrm{~nm}$ and a minor maximum at $375 \mathrm{~nm}$ (Fig. 2). The fluorescence emission spectrum of the reaction solution of

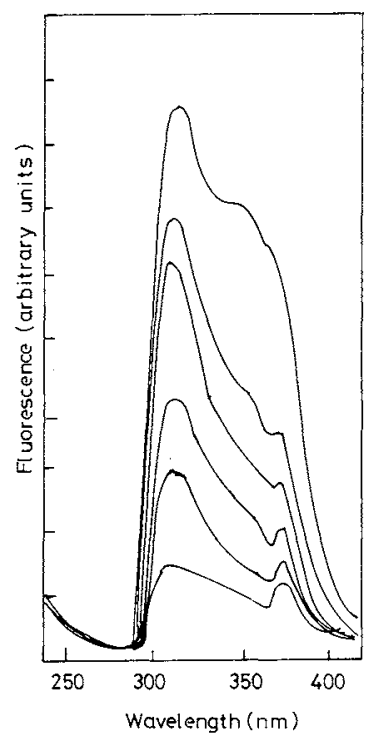

Fig. 2. Fluorescence Excitation Spectra of the Reaction Solution of D-Fructose 6-Phosphate with dGMP.

The reaction solutions in Fig. 1 were diluted 6-fold and fluorescence excitation spectra were recorded at $420 \mathrm{~nm}$ emission wavelength. The concentration of $\mathrm{D}$-fructose 6-phosphate was, from top to bottom, 150, 100, 75, 50, 25 , and $10 \mathrm{~mm}$.
D-fructose 6-phosphate with dGMP, measured at excitation of $315 \mathrm{~nm}$, showed a major emission maximum at $420-440 \mathrm{~nm}$ (Fig. 3). The development of a new fluorescent is similar to those obtained with the nonenzymatic glycation of proteins ${ }^{14)}$ and with DNA glycation by aldoses. $^{5)}$

To examine the difference in reactivities among nucleotides or polymer DNAs, individual deoxyribonucleotides, native, doublestranded DNA, or denatured, single-stranded DNA was incubated with D-fructose 6phosphate, and the development of fluorescence was compared. The development of fluorophores was high in the reaction of D-fructose 6-phosphate with dGMP and dAMP, but very low with TMP (Fig. 4). The spectral properties of the fluorescence were slightly different among nucleotides used. The development of fluorophores was also higher with denatured, single-stranded DNA than with native, double-stranded DNA. These results indicate that the presence of a free primary amino group of DNA is required for development of chromophores and of fluorophores by ketoses, as reported with aldoses by Bucala et al. ${ }^{5)}$
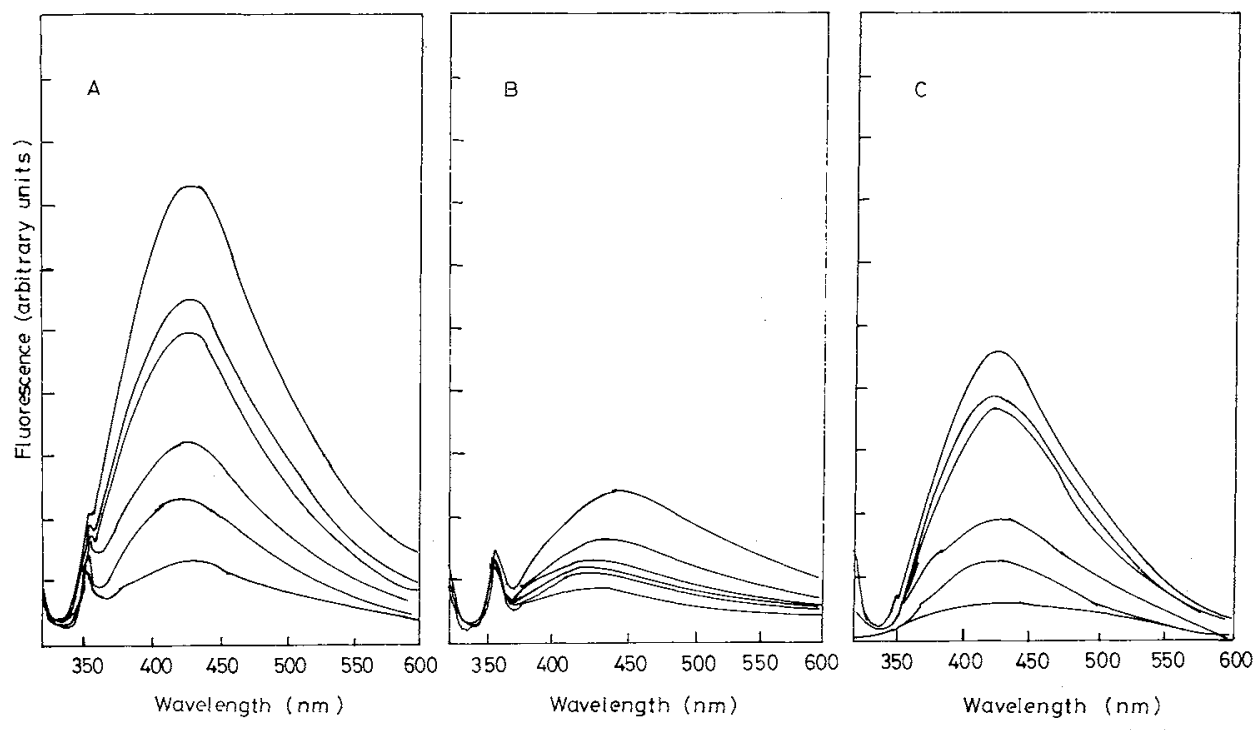

Fig. 3. Fluorescence Emission Spectra of the Reaction Solution of D-Fructose 6-Phosphate with dGMP.

The reaction solutions in Fig. 1 were diluted 6-fold and fluorescence emission spectra were recorded at $315 \mathrm{~nm}$ excitation wavelenth. A, D-fructose 6-phosphate and dGMP; B, D-fructose 6-phosphate alone; C, difference $\operatorname{spectra}(\mathrm{A}-\mathrm{B})$. 


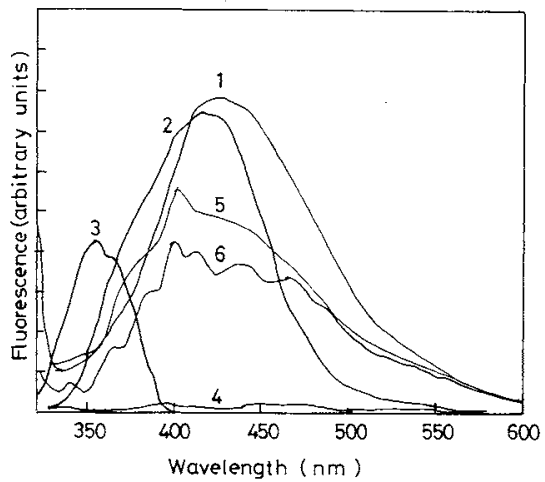

Fig. 4. Fluorescence Emission Difference Spectra of Glycated DNA.

Seventy-five mM D-fructose 6-phosphate was incubated with $10 \mathrm{~mm}$ deoxyribonucleotides (curve 1, dGMP; curve 2, dAMP; curve 3, dCMP; curve 4, TMP), $2 \mathrm{mg} / \mathrm{ml}$ heatdenatured, single-stranded DNA (curve 5 ) or $2 \mathrm{mg} / \mathrm{ml}$ calf thymus DNA (curve 6) for 4 days at $37^{\circ} \mathrm{C}$ in $50 \mathrm{~mm}$ Hepes buffer ( $\mathrm{pH} 8.0$ ) containing $0.5 \mathrm{~mm}$ EDTA. Excitation wavelength was $315 \mathrm{~nm}$.

Table I. EfFects of Aminoguanidine-HCl AND Sodium Cyanoborohydride on the Formation OF FLUORESCENCE DURING THE REACTION OF D-Fructose 6-Phosphate With dGMP

\begin{tabular}{lcc}
\hline Additives & $\begin{array}{c}\text { Conc. } \\
\text { (mM) }\end{array}$ & $\begin{array}{c}\text { Fluorescence } \\
(\text { Ex } 315 \mathrm{~nm}, \\
\text { Em } 420 \mathrm{~nm})\end{array}$ \\
\hline Exp. 1 $\mathrm{NaCNBH}_{3}$ & 0 & $0.063(-)^{b}$ \\
& 0.1 & $0.077(-22)$ \\
& 0.5 & $0.090(-43)$ \\
& 1 & $0.066(-5)$ \\
& 5 & $0.047(25)$ \\
& 10 & $0.039(38)$ \\
Exp. 2 Aminoguanidine-HCl & 0 & $0.127(-)$ \\
& 0.1 & $0.128(-1)$ \\
& 1 & $0.088(31)$ \\
& 5 & $0.007(94)$ \\
& 10 & $0.010(92)$ \\
& &
\end{tabular}

Seventy-five mм (Exp. 1) or $150 \mathrm{~mm}$ (Exp. 2) D-fructose 6-phosphate and $10 \mathrm{~mm}$ dGMP were incubated for 4 days at $37^{\circ} \mathrm{C}$ in $50 \mathrm{~mm}$ Hepes buffer $(\mathrm{pH} 8.0)$ in the presence of the indicated concentration of aminoguanidine- $\mathrm{HCl}$ (Exp. 1) or sodium cyanoborohydride (Exp. 2).

a Fluorescence emission (excitation fixed at $315 \mathrm{~nm}$ ) was measured by subtraction of those of solutions of D-fructose 6-phosphate with sodium cyanoborohydride (Exp. 1) or with aminoguanidine- $\mathrm{HCl}$ (Exp. 2).

$b$ Numbers in parentheses show percent of inhibition.
Table II. EfFects of Chelating Agents And Metal Ions on the Formation of Fluorescence DURING THE REACTION OF D-FRUCTOSE 6-PHOSPHATE WITH dGMP

\begin{tabular}{lccc}
\hline Additives & $\begin{array}{c}\text { Conc. } \\
(\mathrm{mM})\end{array}$ & $\begin{array}{c}\text { Absorbance }^{a} \\
(330 \mathrm{~nm})\end{array}$ & $\begin{array}{c}\text { Fluorescence }^{a} \\
(E x 315 \mathrm{~nm}, \\
\text { Em } 420 \mathrm{~nm})\end{array}$ \\
\hline EDTA & $-\overline{1}$ & $0.150(100)^{b}$ & $0.110(100)^{b}$ \\
DETAPAC & 0.1 & $0.327(218)$ & $0.100(91)$ \\
Citrate & 0.1 & $0.087(58)$ & $0.029(26)$ \\
Desferal & 0.05 & $0.008(5)$ & $0.002(2)$ \\
$\mathrm{CuCl}_{2}$ & 0.01 & $0.311(207)$ & $0.151(137)$ \\
$\mathrm{FeSO}_{4}$ & 0.01 & $0.222(148)$ & $0.125(114)$ \\
$\mathrm{FeCl}_{3}$ & 0.01 & $0.226(151)$ & $0.142(129)$ \\
$\mathrm{MnSO}_{4}$ & 0.01 & $0.262(175)$ & $0.115(105)$ \\
$\mathrm{ZnSO}_{4}$ & 0.01 & $0.155(103)$ & $0.108(98)$ \\
$\mathrm{CoCl}_{2}$ & 0.01 & $0.159(106)$ & $0.100(91)$ \\
$\mathrm{NiCl}_{2}$ & 0.01 & $0.170(113)$ & $0.099(90)$ \\
$\mathrm{MgCl}_{2}$ & 0.01 & $0.172(114)$ & $0.096(87)$ \\
\hline
\end{tabular}

Seventy-five $\mathrm{mM}$ D-fructose 6-phosphate and $10 \mathrm{~mm}$ dGMP were incubated for 4 days at $37^{\circ} \mathrm{C}$ in $50 \mathrm{~mm}$ Hepes buffer ( $\mathrm{pH} \mathrm{8.0)}$ in the presence of indicated additives.

a DATA (D-fructose 6-phosphate+dGMP)-DATA (D-fructose 6-phosphate alone).

$b$ Numbers in parentheses show relative values.

\section{Effects of aminoguanidine and sodium cyano- borohydride}

Recently, Brownlee et al. ${ }^{15)}$ reported that aminoguanidine, a nucleophilic hydrazine compound, inhibited the formation of the advanced glycation products in vivo and in vitro, by a mechanism which involved specific trapping of the Amadori products and/or carbonyl intermediates ${ }^{16)}$ such as 3-deoxyglucosone, yielded via the Amadori products. The effects of aminoguanidine on the formation of fluorescent, advanced nonenzymatic glycation products in the reaction mixture was examined. As shown in Table I, aminoguanidine completely prevented the formation of fluorophores in the reaction solutions, but not chromophores (results not shown). The results suggest that the Heyns products and/or carbonyl intermediates ${ }^{16)}$ such as 3-deoxyglucosone are produced by the glycation of DNA. Inhibition of the reaction by sodium cyanoborohydride $\left(\mathrm{NaCNBH}_{3}\right)$, which selectively reduces Schiff's bases and inhibits the 
Amadori rearrangement, ${ }^{17,20)}$ was also observed (Table I). Although low concentrations of $\mathrm{NaCNBH}_{3}$ promoted the formation of fluorophores somewhat for unknown reasons, high concentrations of $\mathrm{NaCNBH}_{3}$ inhibited the formation of fluorescence. These results indicate that the Maillard reaction between DNA and ketoses proceeds through Schiff's bases and the Heyns products, as described for protein glycation by ketoses. ${ }^{17-20)}$

\section{Effects of metal-chelating agents and metal ions}

Metal-chelating agents such as diethylenetriamine pentaacetic acid (DETAPAC), citrate, and Desferal inhibited the browning and the formation of fluorophores (Table II). Monosaccharides can autoxidize by a transition metal-catalyzed reaction, generating oxygen radicals, free radical intermediates, and dicarbonyl compounds. ${ }^{1,12)}$ The addition of EDTA promoted the reaction. This may be due to the formation of an EDTA-metal complex having higher catalytic activity. ${ }^{21,22)}$ The pro- vision of exogenous $\mathrm{Cu}^{2+}, \mathrm{Fe}^{3+}, \mathrm{Fe}^{2+}$, and $\mathrm{Mn}^{2+}$ stimulated the reaction, but not very effectively. Our system may already contain high enough concentrations of catalytic transition metals.

The results indicate that the metal-catalyzed autoxidation reaction of D-fructose 6-phosphate and/or of glycated products contributes to the browning and the formation of fluorophores in the Maillard reaction of ketoses with DNA.

\section{Effects of radical scavengers}

Since oxygen radicals are generated in the process of autoxidation of reducing sugars, ${ }^{11,12)}$ the effects of SOD and catalase on the fluorescence development reaction were examined. As shown in Fig. 5, SOD and catalase partially inhibited the fluorescence development. The extent of inhibition was maximum at $5 \mu \mathrm{g} / \mathrm{ml}$ of SOD (about $44 \%$ ) or at $10 \mu \mathrm{g} / \mathrm{ml}$ of catalase (about $41 \%$ ). Since heat-inactivated enzymes did not inhibit the
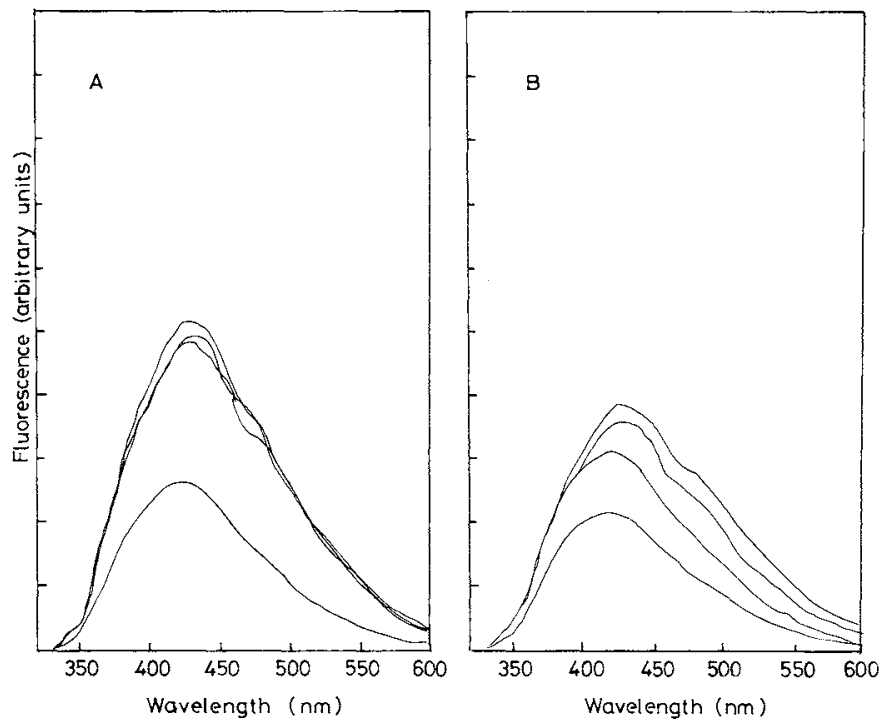

Fig. 5. Effects of Superoxide Dismutase and Catalase on the Formation of Fluorescence during the Reaction of $\mathrm{D}$-Fructose 6-Phosphate with dGMP.

One hundred fifty mM D-fructose 6-phosphate was incubated with or without $10 \mathrm{~mm}$ dGMP for 4 days at $37^{\circ} \mathrm{C}$ in $50 \mathrm{mM}$ Hepes buffer ( $\mathrm{pH} 8.0$ ) in the presence of the indicated concentration of SOD (A) or catalase (B). Fluorescence emission difference spectra (excitation fixed at $315 \mathrm{~nm}$ ) were measured versus solutions without dGMP.

A, from top to bottom, 0,5 (heat-denatured), $0.125,5 \mu \mathrm{g} / \mathrm{ml} \mathrm{SOD} ; \mathrm{B}$, from top to bottom, 10 (heat-denatured), $0,5,10 \mu \mathrm{g} / \mathrm{ml}$ catalase. 
Table III. EFFECTS OF RAdical SCAVEnGers ON THE Formation of FLUORESCENCE DURING THE REACTION OF D-FRUCTOSE 6-Phosphate WITH dGMP

\begin{tabular}{lccc}
\hline \multicolumn{1}{c}{ Additives } & $\begin{array}{c}\text { Conc. } \\
(\mathrm{mM})\end{array}$ & $\begin{array}{c}\text { Inhibition of } \\
\text { Absorbance } \\
(\%)(330 \mathrm{~nm})\end{array}$ & $\begin{array}{c}\text { Inhibition of } \\
\text { fluorescence } \\
(\%)\end{array}$ \\
& & & $\begin{array}{c}(\mathrm{E}) 315 \mathrm{~nm}, \\
E m 420 \mathrm{~nm})\end{array}$ \\
\hline Potassium iodide & 100 & 70 & Promoted \\
Sodium formate & 10 & 0.4 & 8.6 \\
Sodium benzoate & 10 & 1.8 & $-^{a}$ \\
D-Mannitol & 50 & 6.8 & 6.2 \\
\hline
\end{tabular}

One hundred fifty $\mathrm{mM}$ D-fructose 6 -phosphate and $10 \mathrm{mM}$ dGMP were incubated for 4 days at $37^{\circ} \mathrm{C}$ in $50 \mathrm{~mm}$ Hepes buffer ( $\mathrm{pH} 8.0$ ) in the presence of indicated additives.

a Not measured because of fluorescence from sodium benzoate itself.

Table IV. INCREASING OF FluORESCENCE AND Absorbance DURING the REACTION OF REDUCING MONOSACCHARIDES WITH dGMP

\begin{tabular}{|c|c|c|}
\hline Monosaccharides & $\begin{array}{c}\text { Absorbance } \\
(330 \mathrm{~nm})\end{array}$ & $\begin{array}{l}\text { Fluorescence }^{a} \\
(E x 315 \mathrm{~nm} \\
E m 420 \mathrm{~nm})\end{array}$ \\
\hline D-Glucose 6-phosphate & 0.019 & 0.003 \\
\hline D-Galactose 6-phosphate & 0.207 & 0.041 \\
\hline D-Mannose 6-phosphate & 0.097 & 0.015 \\
\hline D-Fructose 6-phosphate & 1.260 & 0.124 \\
\hline D-Fructose 1,6-phosphate & 0.710 & 0.151 \\
\hline D-Ribose 5-phosphate & 1.878 & 0.013 \\
\hline D-Glucose 1-phosphate & 0.026 & 0.007 \\
\hline D-Glucose & 0.001 & 0.001 \\
\hline D-Galactose & 0.001 & 0.001 \\
\hline D-Mannose & $<0.001$ & $<0.001$ \\
\hline D-Fructose & 0.033 & 0.002 \\
\hline D-Ribose & 0.089 & 0.013 \\
\hline D-Arabinose & 0.020 & 0.001 \\
\hline $\mathrm{D}-$ Xylose & 0.036 & 0.004 \\
\hline D-Lyxose & 0.071 & 0.001 \\
\hline
\end{tabular}

One hundred $\mathrm{mm}$ reducing monosaccharide was incubated with or without $10 \mathrm{~mm}$ dGMP for 4 days at $37^{\circ} \mathrm{C}$ in $50 \mathrm{~mm}$ Hepes buffer ( $\mathrm{pH} 8.0$ ) containing $0.5 \mathrm{mM}$ EDTA.

a DATA (monosaccharide + dGMP) - DATA (monosaccharide alone).

reactions, this was not the result of competitive inhibition between enzymes and nucleotides. The increase of fluorescence that was observed upon the addition of $10 \mu \mathrm{g} / \mathrm{ml}$ of SOD may be due to the Maillard reaction of $D$-fructose 6-phosphate with higher concentrations of
SOD, as reported previously. ${ }^{23)}$ Thus, superoxide and hydrogen peroxide are suggested to be involved in the Maillard reaction of DNA with D-fructose 6-phosphate. However, scavengers for hydroxyl radicals, such as potassium iodide, sodium formate, sodium benzoate and D-mannitol, did not inhibit the reaction very effectively (Table III). This could be explained as follows: radical scavengers for hydroxyl radicals could not react with hydroxyl radicals that were formed near the target molecules in a site-specific manner as described by Samuni et al. $^{24)}$

\section{Reaction of monosaccharides with dGMP}

The reactivities of various monosaccharides with deoxyribonucleotides were compared (Table IV). Phosphorylated monosaccharides produced higher levels of browning and fluorescence. The order was also coincident with their autoxidizing abilities. ${ }^{1,12)}$ Fluorescence with D-ribose 5-phosphate was very low in spite of the highest browning. This is due to the quenching effect by high levels of fluorophores, because, with 24-fold diluted samples, D-ribose 5-phosphate had the higest fluorescence. Such differences in the extent of glycation seen with these monosaccharides are considered to be due to differences in the level of free carbonyl groups that are available for initial Schiff's base formation and also for reaction with oxygen. ${ }^{10,25)}$

\section{Discussion}

D-Fructose reacts with proteins in neutral aqueous solutions at $37^{\circ} \mathrm{C}$, forming colored, fluorescent derivatives. ${ }^{7,8)}$ Our results show that several days of incubation of $D$-fructose 6-phosphate with DNA produced chromophores and fluorophores. This verifies that ketoses such as D-fructose 6-phosphate can react also with primary amino group of DNA bases to form Schiff's bases that undergo the Heyns rearrangement, as reported with protein glycation by ketoses. It is unclear whether the structures of chromophores and fluorophores produced in the Maillard re- 
action by ketoses are identical to those described with nonenzymatic glycation by $\mathrm{D}$ glucose.

In an alkaline solution, D-glucose easily isomerizes to D-fructose via the 1,2-enediol anion. ${ }^{26)}$ In some organs, such as the ocular lens and peripheral nerves, D-fructose is biosynthesized by oxidation of sorbitol in a reaction catalyzed by polyol dehydrogenase, ${ }^{27)}$ and then converted to D-fructose 6-phosphate by hexokinase. D-Glucose 6-phosphate can be isomerized to D-fructose 6-phosphate by phosphoglucose isomerase.

Since, in diabetic subjects, the concentration of D-fructose often approaches, and sometimes exceeds, those of D-glucose in ocular lens ${ }^{28}$ ) and in nerves, ${ }^{29)}$ the concentration of $\mathrm{D}$ fructose 6-phosphate could increase with $\mathrm{D}$-fructose concentration. Thus, by analogy with glycation by aldoses, it is conceivable that nonenzymatic glycation by ketoses occurs in some mammalian tissues and that this contributed to diabetic complications. As is known, ketoses are more highly reactive with amino groups than aldoses. ${ }^{10}$ Further, the aldehydic Amadori groups (i.e., of the Heyns products) resulting from glycation with ketoses are highly reactive and facilitate a faster conversion of these groups to fluorophores, compared with ketonic groups of the Amadori products. ${ }^{7,8)}$ Ketoses appear to be important reactants in nonenzymatic glycation in this respect.

Wolff and Dean ${ }^{17-19)}$ have reported that besides direct glycation, the process of glucose oxidation is important in the protein glycation reaction. Our results indicate that a transition metal ion-catalyzed autoxidation reaction is partially involved in the glycation of DNA bases and subsequent formation of chromophores and of fluorophores. Similar results were obtained with DNA glycation by aldoses. ${ }^{30 \text { ) }}$

Three stages are considered for the generation process of oxygen radicals during the Maillard reaction. (1) Monosaccharide autoxidation; monosaccharides cause transition metal-catalyzed autoxidation via enediol anion intermediates, generating superoxide, hydrogen peroxide, and hydroxyl radicals, as well as dicarbonyl compounds. These oxygen radicals may promote the generation of dicarbonyl compounds from radical oxidation of monosaccharides, and the oxidation of glycated products on DNA to develop fluorophores. Dicarbonyl compounds produced by monosaccharide autoxidation can attach to amino groups in DNA involved in the glycation. The increased rate of fluorescence generation with D-fructose 6-phosphate is possibly due to the higher autoxidation activities of phosphoryl ketoses than aldoses. (2) Autoxidation of the Amadori or Heyns products; the Heyns products as well as the Amadori products can also enolize and thereby reduce molecular oxygens under physiological conditions, yielding oxygen radicals and dicarbonyl compounds. These dicarbonyl compounds may be involved in the glycation reaction and subsequent formation of fluorescent compounds. (3) Autoxidation of dicarbonyl compounds generated from oxidation of the Amadori or Heyns products. Although it is not clear which stage of oxygen radical generation is most important for DNA glycation and subsequent formation of fluorescence compounds, beside direct glycation ${ }^{1)}$ with monosaccharides, oxygen radicals and dicarbonyl compounds generated from autoxidation process should be concerned in DNA glycation and subsequent generation of fluorophores. It is unclear whether the structures of fluorophores produced via direct glycation (the classically defined Maillard reaction) are different from those produced via autoxidation process. Upon the addition of SOD or catalase, the emission peak shifted from $440 \mathrm{~nm}$ to $420 \mathrm{~nm}$ (Fig. 5).

The damage of DNA has been hypothesized to be involved in mutagenesis, carcinogenesis, biological aging, and cancer chemotherapy. ${ }^{31)}$ DNA glycation is a covalent modification of DNA and will damage the function of DNA (replication and transcription) as well as many alkylating agents. In addition, it would be expected that glycated DNA contributes to "site-specific" radical DNA damage. ${ }^{24)}$ The 
Amadori products and 2-amino-2-deoxy aldose are known to have higher autoxidizing and DNA strand breakage activities than aldoses or ketoses. ${ }^{32-34)}$ Glycated protein are also found to autoxidize to yield oxygen radicals $^{35,36)}$ and induce DNA strand breakage. ${ }^{37)}$ If the Amadori or Heyns products are formed on DNA or on proteins bound to DNA, then they must autoxidize and produce highly reactive oxygen radicals and other free radicals in the neighborhood of DNA molecules, and thereby may easily cause secondary critical damage to DNA (e.g., strand breakage and further degradation of DNA) as well as the development of fluorophores and chromophores.

\section{References}

1) J. E. Hodge, Adv. Carbohydr. Chem., 10, 169 (1985).

2) M. Roth, Clin. Chem., 29, 199 I (1983)

3) J. J. Harding, Adv. Prot. Chem., 37, 247 (1985).

4) V. M. Monnier, in "The Maillard Reaction in Aging, Diabetes, and Nutrition," ed. by J. W. Baynes and V. M. Monnier, Alan R. Liss, Inc., New York, 1989, pp. 1-22.

5) R. Bucala, P. Model and A. Cerami, Proc. Natl. Acad. Sci. U.S.A., 81, 105 (1984).

6) A. T. Lee and A. Cerami, Proc. Natl. Acad. Sci. U.S.A., 84, 8311 (1987).

7) G. Suárez, R. Rajaram, K. C. Bhuyan, A. L. Oronsky and J. A. Goidl, J. Clin. Inv., 82, 624 (1988).

8) G. Suárez, R. Rajaram, A. L. Oronsky and M. A. Gawinowicz, J. Biol. Chem., 264, 3674 (1989).

9) J. D. McPherson, B. H. Shilton and D. J. Walton, Biochemistry, 27, 1901 (1988).

10) H. F. Bunn and P. J. Higgins, Science, 213, 222 (1981).

11) N. Kashimura, J. Morita and T. Komano, Carbohydr. Res., 70, C3 (1979).

12) P. J. Thornalley, Environ. Health Perspectives, 64 , 297 (1985).

13) J. Morita and T. Komano, Agric. Biol. Chem., 47, 11 (1983).

14) S. Pongor, P. O. Ulrich, F. A. Bencsath and A. Cerami, Proc. Natl. Acad. Sci. U.S.A., 81, 2684 (1984).

15) M. Brownlee, H. Vlassara, A. Kooney, P. Ulrich and A. Cerami, Science, 232, 1629 (1986).

16) M. Oimomi, N. Igaki, H. Sakai, T. Ohara, S. Baba and H. Kato, Agric. Biol. Chem., 53, 1727 (1989).

17) S. P. Wolff and R. T. Dean, Biochem. J., 245, 243 (1987)

18) S. P. Wolff and R. T. Dean, Bioelectrochem.
Bioenerg., 18, 283 (1987).

19) J. V. Hunt, R. T. Dean and S. P. Wolff, Biochem. $J ., 256,205$ (1988)

20) E. Abraham, C. Tsai, A. Abraham and M. Swamy, in "The Maillard Reaction in Food Processing, Human Nutrition and Physiology," ed. by P. A. Finot, H. U. Aeschbacher, R. F. Hurrell and R. Liardon, Birkhäuser Verlag, Basel, 1990, pp. 437-448.

21) C. C. Winterbourn and H. C. Sutton, Arch. Biochem. Biophys., 244, 27 (1986).

22) E. Graf, J. R. Mahoney, R. G. Bryant and J. W. Eaton, J. Biol. Chem., 259, 3620 (1984).

23) K. Arai, M. Maguchi, S. Fujii, H. Ishibashi, K. Oikawa and N. Taniguchi, J. Biol. Chem., 262, 16969 (1987).

24) A. Samuni, J. Aronovitch, D. Godinger, M. Chevion and G. Czapski, Eur. J. Biochem., 137, 119 (1983).

25) H. S. Isbell, Carbohydr. Res., 49, Cl (1976).

26) G. de Wit, A. P. G. Kieboom and H. van Bekkum, Carbohydr. Res., 74, 157 (1979).

27) K. H. Gabbay, Annu. Rev. Med., 26, 521 (1975).

28) J. A. Jedziniak, L. T. Chylack Jr, H.-M. Cheng, K. M. Gillis, A. A. Kalustian, W. H. Tung, Invest. Ophthalmol Visual Sci., 20, 314 (1981); S. D. Varma, S. S. Schocket and R. D. Richards, Invest. Ophthalmol Visual Sci., 18, 237 (1979).

29) J. A. Mayhew, K. R. W. Gillon, J. N. Hawthorne, Diabetologia, 24, 13 (1983).

30) J. Morita and N. Kashimura, in "The Maillard Reaction in Food Processing, Human Nutrition and Physiology," ed. by P. A. Finot, H. U. Aeschbacher, R. F. Hurrell and R. Liardon, Birkhäuser Verlag, Basel, 1990, pp. 505-510.

31) B. N. Ames, Science, 221, 1256 (1985).

32) N. Kashimura, J. Morita, I. Sato, Z. Kumazawa, S. Nishikawa, S. Ito, Y. Koma and M. Komada, in "Amino-Carbonyl Reaction in Food and Biological Systems," ed. by H. Kato and M. Namiki, Elsevier, Amsterdam, 1986, pp. 401-410.

33) N. Kashimura, J. Morita, K. Sugiura, S. Nishikawa and Z. Kumazawa, in "The Role of Oxygen in Chemistry and Biochemistry," ed. by W. Ando Y. Moro-oka, Elsevier, Amsterdam, 1987, pp. $483-488$

34) S. Nanjou, S. Fujii, J. Morita, K. Ueda and T. Komano, Biochim. Biophys. Acta, 866, 44 (1986).

35) G. Gillery, J. C. Monboisse, F. X. Maquart, J. P. Borel, Diabetes and Metabolism, 14, 25 (1988).

36) T. Sakurai, K. Sugioka and M. Nakano, Biochim. Biophys. Acta, 1043, 27 (1990).

37) N. Kashimura, J. Morita, S. Nishikawa and Z. Kumazawa, in "The Maillard Reaction in Food Processing, Human Nutrition and Physiology," ed. by P. A. Finot, H. U. Aeschbacher, R. F. Hurrell and R. Liardon, Birkhäuser Verlag, Basel, 1990, pp. $449-454$ 